\title{
HABILIDADES EM COMPREENSÃO DA LEITURA: UM ESTUDO COM ALUNOS DE PSICOLOGIA
}

\author{
READING COMPREHENSION ABILITIES: \\ A STUDY WITH PSYCHOLOGY STUDENTS
}

\author{
Acácia A. Angeli dos SANTOS* \\ Adriana C. B. SUEHIRO** \\ Katya Luciane de OLIVEIRA***
}

\begin{abstract}
RESUMO
Este estudo objetivou analisar a relação entre a compreensão em leitura e o rendimento acadêmico em disciplinas específicas do curso de Psicologia. Participaram 115 universitários ingressantes de uma universidade do interior paulista. Foram aplicados dois textos preparados segundo a técnica de Cloze e um questionário com questões fechadas, visando identificar os tipos de avaliação de aprendizagem utilizados pelos professores. Os resultados obtidos evidenciaram a existência de índices de correlação positiva entre os escores somados dos testes de Cloze e as notas obtidas em cada disciplina cursada. Pode-se concluir que a compreensão em leitura relaciona-se com o desempenho acadêmico, especialmente quando a nota é resultante de uma produção individual do aluno na situação de avaliação.
\end{abstract}

Palavras-chave: Desempenho acadêmico; Teste de Cloze; Estratégias de aprendizagem.

\begin{abstract}
This research meant to explore the relation among reading comprehension and academic performance in specific contents of the Psychology course. The sample was composed of by 115 freshman students of the private university in São Paulo. The instruments used were two texts prepared in
\end{abstract}

(*) Psicóloga, Doutora em Psicologia Escolar pela USP e Docente do programa de Estudos Pós-Graduados em Psicologia da Universidade São Francisco (USF). Endereço para Correspondência: R. Alexandre Rodrigues Barbosa, 45 - Itatiba/SP - CEP 13251-900 - E-mail: acacia.santos@saofrancisco.edu.br

(*) Mestranda do Programa de Estudos Pós-Graduados em Psicologia da Universidade São Francisco (USF) - Utatiba/SP - Bolsista CAPES.

(*) Doutoranda da Faculdade de Educação da UNICAMP - Docente da Universidade de Alfenas/MG (UNIFENAS). 


\begin{abstract}
accordance to Cloze's technique and a questionnaire focusing the most used characterization types in higher education assessment. The results showed clearly a correlation, statistically significant, among reading comprehension, academic performance and learning assessment in Psychology course, specially when the grade results of the student individual production in assessment situation.
\end{abstract}

Key words: Academic performance; Cloze Test; Learning strategies.

\section{INTRODUÇÃO}

A identificação de falhas existentes no processo de ensino e aprendizagem pretendida no ensino superior tem inquietado e desafiado pesquisadores do mundo todo a se debruçarem sobre essa questão, trazendo luzes sobre a compreensão do fenômeno e buscando alternativas de superação para as dificuldades detectadas (Flippo \& Caverly, 1991; Santos, 1991; Witter, 1997; Spires \& Donley, 1998; Almeida, Soares \& Ferreira, 1999).

Existem queixas constantes de professores universitários brasileiros referentes às dificuldades de aprendizagem apresentadas pelos seus alunos. No seu conjunto se referem a problemas relacionados à integração de novas informações e conhecimentos, quer contextualizando-os em seus aspectos históricos e sociais, quer relacionando-os com os recentes avanços da ciência e tecnologia. Tal situação leva a crer que não se pode contar com desempenhos acadêmicos que exijam estratégias de processamento cognitivo de profundidade (Marton, Hounsell \& Entwistle, 1984).

Muitas pesquisas têm constatado que a falta de compreensão tem sido um obstáculo para muitos estudantes que apresentam dificuldades na leitura e no aprendizado de textos. Diferentes estudos têm apontado que nem sempre os estudantes apresentam o desempenho esperado para atender às exigências acadêmicas relativas ao seu nível de escolaridade (Egypto, 1983; Marini, 1986; Armbruster \& cols., 1990; Santos, 1990, 1991; Pellegrini, 1996; Santos, 1997; Witter, 1997; Sampaio \& Santos, 2002; Suehiro \& Santos, 2002).
Considerando essas exigências, imprescindíveis para uma formação no ensino superior, vale ressaltar que a leitura é um importante instrumento de aprendizagem e que ocupa um papel de grande relevância na vida de um indivíduo. Considera-se que ela não só representa o primeiro passo para a assimilação dos valores da sociedade e para a formação de cidadãos, mas também é por meio dela que se adquire uma percepção singular do mundo que permite refletir, questionar e avaliar as informações com base em seu próprio referencial (Drouet, 1995; Ellis, 1995; Gregoire \& Pérart, 1997).

Pesquisas sobre o comportamento de leitura, como a de Santos (1990), têm se preocupado em demarcar o processo de compreensão e caracterizar as diferenças entre um leitor em nível elementar e um leitor competente. Davis e cols. (1989) lembram que alguns fatores interferem no processo de compreensão, estando relacionados às características do sujeito, entre os quais, os conhecimentos prévios e o interesse pelo assunto. Além disso, ressaltam que outras variáveis, inerentes ao texto, tais como sua estrutura e a complexidade do vocabulário, podem também ser determinantes para a compreensão do que se lê.

Nesse contexto, faz-se presente o sentido interativo dos elementos básicos da leitura: o autor, o texto e o leitor. Ao realizar a transferência de significados e apreender o sentido proposto pelo autor no texto, o leitor relaciona novos conhecimentos aos já existentes e os reorganiza para incorporar e trabalhar com a nova informação. De acordo com essa perspectiva, a competência de leitura está diretamente relacionada aos conceitos, valores e conhecimentos prévios que o estudante apresenta. Segundo Ayres (1999), 
para que um indivíduo seja capaz de compreender algo é preciso que tenha condições de fazer as associações adequadas. Assim, tanto a leitura quanto o aprendizado estão relacionados a um processo de modificação de informações que o leitor já possui e isso se deve a constantes interações com o contexto em que se encontra inserido.

Em consonância com estudiosos da área, Carelli (1992) afirma que a habilidade de compreensão em leitura implica a relação de novos conhecimentos com antigos, a organização do conhecimento e sua recordação. Modelos mais recentes de ensino têm trabalhado com os conhecimentos prévios dos estudantes, por acreditarem que o leitor utiliza várias fontes de conhecimento para construir o significado de um texto, incluindo sua cultura e experiência. De acordo com esta concepção, os conhecimentos apresentados pelo leitor facilitam a compreensão do texto, permitindo o estabelecimento de relações, a geração de conclusões e a capacidade de fazer predições (Kintsch \& van Dijk, 1978; Kintsch, 1988; Smith, 1989; Kleiman, 1999).

No mesmo sentido, Spires e Donley (1998) afirmam que pesquisas têm demonstrado que leitores que possuem níveis altos de conhecimento exibem constantemente uma melhor compreensão e retenção de textos que os leitores com baixo nível de conhecimento. No entanto, Gurthrie e cols. (1998) consideram que a diferença entre os bons e os maus leitores parece não se resumir apenas à quantia disponível de conhecimento, mas também à forma como tais conhecimentos são recuperados e utilizados para a compreensão de um texto.

Quando o leitor lança mão de estratégias adequadas e traz seus conhecimentos pessoais para o contexto escolar, assumindo a posição de sujeito-leitor, interessa-se mais pelos textos acadêmicos e passa a construir uma relação mais significativa com a tarefa de leitura. Esta relação não só torna o leitor mais comprometido com sua compreensão, mas também permite que o estudante desenvolva o auto-respeito, a auto-realização e a segurança, transformando a leitura em um meio de aprendizagem, de lazer e de estímulo ao pensamento (Oliveira, 1996).

Com base nos aspectos destacados, é possível afirmar que a leitura é imprescindível aos universitários, posto que é principalmente por meio dela que se dá o acesso ao conteúdo de diversas disciplinas e à produção científica. Além disso, a leitura é um instrumento importante para que, como leitor competente, o estudante compreenda e utilize, de forma crítica e adequada, as informações obtidas via texto, utilizando-as para compor uma prática profissional eficiente (Witter, 1997).

A complexidade do processo de leitura experimentada pelos universitários e as dificuldades por eles enfrentadas criam a consciência da necessidade de se ler melhor, em função da grande quantidade de informação a ser assimilada em um tempo mínimo (Santos, 1997). Daí a necessidade da implementação de programas de diagnóstico e posterior intervenção, que permitam que o nível de compreensão do aluno seja identificado e que procedimentos educacionais mais adequados sejam empregados, propiciando melhores condições de estudo e conseqüente desempenho acadêmico (Chance, 1985; Santos, 1997; Sampaio \& Santos, 2002).

A leitura, bem como a escrita, não apenas possibilitam o acesso à informação, mas também são atividades cognitivas que favorecem o desenvolvimento de outras habilidades necessárias à realização profissional e pessoal de todo ser humano. A relação entre a leitura e a escrita também tem sido detectada em alguns estudos realizados com universitários, mostrando haver relação entre as habilidades de ler e escrever (Pinheiro, 1994; Arouca, 1997; Sampaio \& Santos, 2002).

Verifica-se, então, a necessidade da utilização de formas eficazes de avaliação da aprendizagem e, mais especificamente, de avaliação do nível de compreensão em leitura dos estudantes do ensino superior, para que as falhas detectadas sejam superadas. Tendo em vista o papel fundamental dessa avaliação, inúmeras pesquisas têm sido realizadas com o 
intuito de torná-la mais prática e construtiva (Sousa, Depresbiteris, Franco \& Sousa, 1995; Almeida, 1997; Sordi, 2000; Luckesi, 2001).

Bzuneck (2001) tem criticado a concepção da avaliação focada no produto final, lembrando a importância de que se avalie o processo de aprendizagem como um todo. Ressalta que o professor deve ser concebido como aquele que utiliza a avaliação muito mais como forma de conduzir seus alunos a perceberem seus erros e fracassos e como oportunidade para o processo de construção do conhecimento e nunca como situação de identificação da falta de capacidade dos mesmos. Complementando, Shigunov (2000) afirma que a avaliação deve ser pensada como um meio para se observar o progresso de cada aluno e funcionar como um processo motivacional positivo.

Diante dessa realidade, a aplicação de provas desempenharia outras funções, além das tradicionais, e a avaliação da aprendizagem passaria a incluir a mediação do pensamento sintético, das aquisições e aplicações da aprendizagem, bem como a metacognição e as estratégias de aprendizagem dos estudantes. De acordo com Sisto (2001), isso contribuiria para que o professor planejasse o ensino de modo a potencializar a aquisição do conhecimento por parte de seus alunos.

É freqüente a constatação que os maus resultados obtidos na avaliação da aprendizagem estão relacionados com as dificuldades em outras habilidades básicas. Estudos, como o de Oliveira e Santos (2003), têm evidenciado que a avaliação da aprendizagem está relacionada a uma boa habilidade de leitura e desempenho acadêmico. No entanto, as instituições de nível superior têm minimizado a importância de se identificar precocemente a habilidade de compreensão em leitura que o universitário ingressante traz, para poder desenvolver programas adequados à remediação dos déficits detectados (Santos \& cols, 2000).

Nesse sentido, observa-se que a técnica de Cloze tem sido adotada com freqüência para diagnosticar a habilidade de compreensão em leitura. A técnica foi desenvolvida por Taylor em 1953 e consiste em eliminar palavras de um texto escrito e colocar traços no lugar dos vocábulos eliminados. Sua aplicação consiste em pedir para que o estudante procure adivinhar as palavras omitidas e escrevê-las nos traços correspondentes que, segundo os padrões tradicionais da técnica, correspondem ao quinto vocábulo.

Embora muitas formas de avaliação da compreensão possam ser utilizadas, o Cloze tem sido considerado como uma das mais adequadas, considerando sua facilidade de construção, aplicação e correção (Sampaio, 1982; Marini, 1986; Nist \& Simpson, 1987, Santos, 1991). Destaca-se que esta técnica pode ser aplicável a assuntos específicos de diferentes disciplinas e que a análise dos erros cometidos permite identificar a necessidade de informações adicionais que devem ser fornecidas aos alunos antes que prossigam em outras leituras sobre 0 tema. Sua utilização pode propiciar ao leitor a ampliação de sua cultura e a aprendizagem de conteúdos específicos de maneira interdisciplinar, o que possibilita a aquisição da competência em leitura e o desenvolvimento da criatividade verbal (Taylor, 1953; Santos, 1997; Santos, Primi, Taxa \& Vendramini, 2002).

Santos (1991), em um estudo sobre leitura com universitários utilizando a técnica de Cloze, e outros estudiosos citados por Marini (1986) verificaram que o nível de compreensão em leitura pode ser preditivo do rendimento acadêmico. Todavia, Oliveira (2001) constatou que, das doze disciplinas focalizadas em seu estudo, apenas seis apresentavam uma correlação significativa entre compreensão em leitura e desempenho acadêmico, obtido por meio de notas cedidas pela secretaria da Instituição de Ensino Superior (IES) focalizada. Tal resultado, de acordo com a autora, causou surpresa, tendo em vista que o rendimento em seis disciplinas, que requeriam intensa atividade de leitura, não apresentou correlação significativa com o nível de compreensão medido pelo teste de Cloze. Com base na análise detalhada dos resultados obtidos, Oliveira (2001) levantou a hipótese de que a baixa relação entre a compreensão de leitura e o 
desempenho acadêmico nessas disciplinas poderia estar relacionada ao tipo de avaliação utilizada pelo professor.

Partindo dessa expectativa, o presente estudo teve por objetivos (a) identificar o desempenho em leitura dos alunos ingressantes com base nos dois testes de Cloze; (b) estabelecer correlações entre a habilidade de compreensão de leitura e o desempenho acadêmico em disciplinas específicas de alunos ingressantes do curso de psicologia; e (c) identificar os tipos de avaliação mais freqüentemente utilizados pelos professores que ministram as disciplinas de conteúdos específicos.

\section{MÉTODO}

\section{Informantes}

Participaram 115 alunos ingressantes do curso de psicologia, de uma universidade particular do interior paulista, com média de idade de 22 anos $(D P=6,97)$, variando de 17 a 53 anos. A maioria dos ingressantes pertence ao gênero feminino $(87,1 \%)$ e ao período noturno $(74,1 \%)$.

\section{Material}

Foram utilizados dois textos adaptados segundo a técnica de Cloze, na sua versão tradicional, com $05^{\circ}$ vocábulo omitido. O primeiro texto intitulava-se "Desentendimento" e era de autoria de Luís Fernando Veríssimo e o outro, denominado "A nova classe dominante" era de autoria de Carlos Heitor Cony. Além disso, foi utilizado um questionário, elaborado por Oliveira e Santos (2003), contendo questões fechadas que versavam sobre as formas de avaliação mais comuns no ensino superior e uma questão aberta, na qual os alunos deveriam apontar uma estratégia a partir da qual o seu desempenho seria melhor avaliado.

\section{Procedimento}

A aplicação foi realizada de forma coletiva, dirigida aos alunos que assinaram o termo de consentimento livre e esclarecido. Para equilibrar eventuais diferenças de dificuldades entre os testes de Cloze, foram montados dois jogos de provas diferentes, nos quais a ordem de apresentação dos textos variava. Durante a coleta de dados, os estudantes respondiam ao questionário sobre as formas de avaliação mais comuns no ensino superior entre os dois textos de Cloze. Os jogos de provas diferentes foram entregues de forma aleatória aos participantes da pesquisa.

\section{RESULTADOS E DISCUSSÃO}

Os resultados foram analisados qualitativa e quantitativamente e, tendo em vista os objetivos pretendidos, utilizaram-se provas de estatística descritiva e a análise de correlação no tratamento dos dados obtidos. Os dados referentes ao objetivo de identificar o desempenho em leitura dos alunos ingressantes com base nos dois

Tabela 1. Desempenho em compreensão de leitura detectado pelo Teste de Cloze ( $N=115)$.

\begin{tabular}{lcccc}
\hline Testes de Cloze & $\begin{array}{c}\text { Pontuação } \\
\text { Média }\end{array}$ & $\begin{array}{c}\text { Pontuação } \\
\text { Mínima }\end{array}$ & $\begin{array}{c}\text { Pontuação } \\
\text { Máxima }\end{array}$ & Desvio-Padrão \\
\hline Cloze 1 - "Desentendimento" & 21 & 9 & 29 & 4,13 \\
Cloze 2 - "A nova classe dominante" & 15 & 8 & 25 & 3,03 \\
Total de pontos nos testes de Cloze & 36 & 20 & 54 & 6,31 \\
\hline
\end{tabular}


testes de Cloze utilizados encontram-se na Tabela 1.

O desempenho no Cloze apresentou altos índices de correlação entre os resultados obtidos nos dois textos aplicados $(r=0,543 ; p<0,001)$. A pontuação máxima possível no teste de Cloze "Desentendimento" era de 46 pontos, enquanto para o Cloze "A nova classe dominante" o número de acertos possíveis era 40. Todavia, nos resultados obtidos, a pontuação máxima alcançada pelos alunos foi, respectivamente, de 29 pontos para o primeiro Cloze (texto 'Desentendimento') e 25 pontos para o segundo Cloze (texto 'A Nova Classe Dominante'). A pontuação somada dos dois testes de Cloze foi de 54 pontos do total de 86 pontos possíveis.

Os resultados obtidos foram similares aos de outros estudos brasileiros e estrangeiros que apontam que os universitários apresentam um nível de compreensão inferior ao desejável, para a etapa de escolarização em que se encontram. Isso Ihes dificulta o acesso, a compreensão e a utilização, de forma crítica e adequada, das informações obtidas via texto para compor uma prática profissional eficiente (Egypto, 1983; Marini, 1986; Santos, 1990, 1991; Armbruster \& cols., 1990; Pellegrini, 1996; Santos, 1997; Witter, 1997; Sampaio \& Santos, 2002; Suehiro \& Santos, 2002).

Com relação ao objetivo de verificar a existência de correlação entre a habilidade de compreensão em leitura e o desempenho acadêmico dos alunos nas diferentes disciplinas, os resultados obtidos estão apresentados na Tabela 2.

A análise revelou a existência de índices de correlação positiva entre os escores somados dos dois testes de Cloze e as notas obtidas nas disciplinas cursadas no primeiro semestre. As disciplinas que apresentaram índices altamente significativos de correlação $(p<0,0001)$ foram História da Psicologia, Fundamentos da Psicologia e Formação Profissional, Psicologia Geral e Citogenética.

Os resultados obtidos são congruentes com os de outras pesquisas que apontam correlações significativas entre compreensão em leitura e desempenho acadêmico (Santos, 1991; Santos, 1997; Oliveira, 2001). Detectar precocemente os alunos que apresentam habilidade de compreensão em leitura inferior à desejável possibilita que professores e instituição implementem procedimentos educacionais mais adequados. Tais procedimentos poderão propiciar melhores condições de estudo e, conseqüentemente, um desempenho acadêmico mais elevado (Chance, 1985; Santos, 1997; Sampaio \& Santos, 2002).

Tendo em vista que a habilidade de compreensão em leitura pode ser preditiva do rendimento acadêmico, é importante ressaltar o papel fundamental que a avaliação da aprendi-

Tabela 2. Correlação entre os escores totais dos Testes de Cloze e o desempenho acadêmico por disciplina $(N=115)$.

\begin{tabular}{lcc}
\hline \multicolumn{1}{c}{ Disciplinas } & Correlação $(r)$ & Significância $(p)$ \\
\hline História da Psicologia & 0,387 & 0,000 \\
Antropologia Cultural & 0,238 & 0,010 \\
Fundamentos da Psicologia e Formação Profissional & 0,450 & 0,000 \\
Filosofia & 0,259 & 0,005 \\
Psicologia Geral & 0,400 & 0,000 \\
Citogenética & 0,383 & 0,000 \\
\hline
\end{tabular}


zagem assume. Assim, este estudo pretendeu também identificar o que os alunos apontaram como estratégias de avaliação que mais influenciaram na sua nota final. As freqüências das respostas e suas respectivas porcentagens estão apresentadas na Tabela 3.

Como pode ser observado, os alunos ingressantes apontaram as "provas dissertativas individuais" como o tipo de avaliação mais freqüentemente utilizado pelos professores das diversas disciplinas, seguidas pelas "provas objetivas (testes) individuais" e pela "apresentação de seminários em grupo". Os tipos de avaliação menos citados foram o "estudo de caso", as "provas objetivas (testes) em grupo" e os "trabalhos dissertativos individuais".

A prova dissertativa individual é um tipo de avaliação instrucional bastante dependente das leituras que o indivíduo faz. Estudos como o de Sousa e cols. (1995) têm destacado que essa faceta da prática avaliativa tem por objetivo diagnosticar, retroinformar e classificar, embora se atribua grande importância ao desempenho do aluno em detrimento da curiosidade na busca pelo conhecimento e, portanto, uma supervalorização desta última função. Lamentavelmente, as provas objetivas (testes) individuais foram apontadas pelos alunos ingressantes como o segundo tipo de avaliação que mais influenciou a sua nota final. Os dados obtidos indicam a necessidade de investigação de procedimentos renovadores que avaliem o processo de aprendizagem como um todo, ao invés de focarem o produto final (Bzuneck, 2001).

A nova realidade educacional de um mundo com uma enorme quantidade de informação que deve ser adequadamente processada exige que a aplicação de provas, além das funções tradicionais, inclua a medição do pensamento sintético, das aquisições e aplicações da aprendizagem, bem como a metacognição e as estratégias de aprendizagem dos estudantes.

Tabela 3. Tipos de avaliação mais freqüentemente citados pelos alunos como tendo sido utilizados pelos professores nas diferentes disciplinas $(N=115)$.

\begin{tabular}{lcc}
\hline Categorias & Freqüência de citações & Porcentagem de citações (\%) \\
\hline Provas Dissertativas Individuais & 233 & 28,9 \\
Respostas em Branco & 101 & 12,5 \\
Provas Objetivas (Testes) Individuais & 94 & 11,7 \\
Apresentação de Seminários em Grupo & 87 & 10,8 \\
Trabalhos Dissertativos em Grupo & 64 & 7,9 \\
Provas Dissertativas em Grupo & 56 & 6,9 \\
Participação em Sala de Aula & 52 & 6,5 \\
Resumos de Livros/Capítulos & 44 & 5,5 \\
Debates em Grupo em Sala de Aula & 39 & 4,8 \\
Trabalhos Dissertativos Individuais & 21 & 2,6 \\
Provas Objetivas (Testes) em Grupo & 10 & 1,2 \\
Estudo de Caso & 05 & 0,6 \\
Total de citações & 806 & 100 \\
\hline
\end{tabular}


Tais funções destacam o papel do aluno enquanto sujeito de sua aprendizagem, o que Ihe atribui maior autonomia, permitindo que o avaliador pense o processo de avaliação da aprendizagem como um meio para observar o progresso e o processo motivacional vivido pelo aluno (Shigunov, 2000).

Além disso, poucas vezes foram apontadas pelos estudantes estratégias como o estudo de caso, os debates em grupo em sala de aula e participações em aula. Tais atividades possivelmente constituiriam momentos de avaliação que permitiriam uma maior exposição do aluno, evidenciando suas atitudes e curiosidades na busca pelo conhecimento. Vale lembrar que, como destaca Sisto (2001), a avaliação pode e deve contribuir para que o professor planeje o ensino de modo a potencializar a real aquisição do conhecimento por parte de seus alunos.

\section{CONCLUSÕES}

A leitura é considerada na universidade como uma das habilidades essenciais para o processo ensino-aprendizagem, posto que é principalmente por meio dela que se dá o acesso ao conteúdo das diversas disciplinas. Assumindo este pressuposto, considera-se que o domínio de habilidades de leitura é imprescindível para o desempenho do estudante nas diversas situações acadêmicas. Assim, julgou-se importante investigar alguns aspectos relacionados à compreensão de textos, ao desempenho acadêmico e ao tipo de avaliação utilizada em disciplinas específicas de um curso universitário (Flippo \& Caverly, 1991; Drouet, 1995; Ellis, 1995; Gregoire \& Pérart, 1997; Almeida, Soares \& Ferreira, 1999; Spires, Williams, Jackson \& Huffman, 1999).

Os principais resultados obtidos permitiram afirmar que o nível de compreensão em leitura dos ingressantes mostrou-se aquém do desejado, assim como seu desempenho acadêmico, o que foi congruente com a literatura da área (Chance, 1985; Santos, 1997; Wittter, 1997; Sampaio \& Santos, 2002).
A análise revelou também que a prova dissertativa individual foi a estratégia de avaliação que mais influenciou na composição da nota final dos ingressantes. Seria desejável que outras formas de avaliação mais inovadoras aparecessem com mais destaque, visando ao aumento da freqüência de atividades de leitura, à utilização da metacognição e ao desenvolvimento da autonomia intelectual dos alunos (Sousa \& cols., 1995; Esteban, 2000; Shigunov, 2000; Bzuneck, 2001).

Embora os objetivos do estudo tenham sido atingidos, é importante que se considerem as limitações metodológicas da presente pesquisa, especialmente no que se refere ao tamanho da amostra e à sua circunscrição a um único curso de uma instituição. Dessa forma, entende-se como necessário que outros trabalhos sejam realizados, possibilitando a exploração do problema investigado com outras amostras, envolvendo outros cursos e áreas, garantindo a ampliação do conhecimento científico sobre o assunto.

\section{REFERÊNCIAS BIBLIOGRÁFICAS}

ALMEIDA, A. M. F. P. M. (1997). Avaliação da aprendizagem e seus desdobramentos. Avaliação, 2 (2-4), 37-50.

ALMEIDA, L. S., SOARES, A. P. C. E., \& FERREIRA, J. A. (1999). Adaptação, rendimento e desenvolvimento dos estudantes no ensino superior. Construção/validação do questionário de vivências acadêmicas. Relatório técnico da investigação, Centro de Estudos em Educação e Psicologia. Universidade do Minho, Braga.

ARMBRUSTER, B., ANDERSON T., ARMSTRONG, J., WISE, M., JANISCH, C. \&. MEYER, L. (1990). Reading and questioning in content area lessons. Champaign: University of Illinois at Urbana - Champaign, Center for the Study of Reading.

AROUCA, E. A. (1997). Validação de um material programado de linguagem escrita aplicado a universitários. (Dissertação de Mestrado), PUC- Campinas. 
AYRES, C. R. (1999). O papel do conhecimento prévio na relação leitura e compreensão. Signo, 24 (37), 71-85.

BZUNECK, J. A. (2001). O esforço nas aprendizagens escolares: mais do que um problema motivacional do aluno. Revista Educação e Ensino - USF, 1 (6), 7-18.

CARELLI, A. E. (1992). Teste da eficiência de programas de compreensão e leitura crítica. Dissertação de Mestrado. Departamento de Pós-Graduação em Biblioteconomia, PUCCAMP, Campinas-SP.

CHANCE, L. (1985). Use Cloze encounters of the readability kind for secundary school students. Journal of Reading, 29, 690-693.

CONY, C. H. (1998). A nova classe dominante. Revista República, n. 17. Ano II.

DAVIS, R. L., DAVIS, C. E., JACOBSON, M. G. \& STAHL, S. A. (1989). Prior knowledge and difficult vocabulary in the comprehension of unfamiliar text. Reading Research Quarterly, 24 (11), 27-41.

DROUET, R. C. R. (1995). Distúrbios da aprendizagem. São Paulo: Ática.

EGYPTO, M. S. R. (1983). Leitura em estudantes universitários: estudo contrastivo de caracterização de nível de desempenho. Dissertação de Mestrado. Universidade Federal da Paraíba. João Pessoa-PB.

ELLIS, A.W. (1995). Leitura, escrita e dislexia: uma análise cognitiva ( $\left.2^{\mathrm{a}} \mathrm{ed}\right)$. Tradução Dayse Batista, Porto Alegre: Artes Médicas.

FLIPPO, R. F. \& CAVERLY, D. C. (1991). College reading and strategy programs. Newark: Ira.

GREGOIRE, J. \& PIÉRART, B. (1997). Avaliação de problemas de leitura: os novos modelos teóricos e suas implicações. Tradução Maria Regina Borges Osório. Porto Alegre: Artes Médicas.

GURTHRIE, J. T., METER, P. V., HANCOCK, G. R., ALAO, S., ANDERSON, E. \& MCCANN, A. (1998). Does concept-oriented reading instruction increase strategy: Use and conceptual learning from text? Journal of Educational Psychology, 90 (2), 261-278.
KINTSCH, W. \& VAN DIJK, T. A. (1978). Toward a model of text comprehension and production. Psychological Review, 85 (5), 363-394.

KINTSCH, W. (1988). The role of knowledge in discourse comprehension a construction -integration model. Psychological Review, 95 (2), 163-182.

KLEIMAN, A. (1999). Texto e leitor: aspectos cognitivos da leitura ( $6^{a}$ ed.). Campinas: Pontes.

LUCKESI, C. C. (2001). Avaliação da aprendizagem escolar: estudos e proposições $\left(11^{\mathrm{a}}\right.$ ed.). São Paulo: Cortez.

MARINI, A. (1986). Compreensão de leitura no ensino superior: Teste de um problema para treino de habilidades. Tese de Doutorado - Instituto de Psicologia. Universidade de São Paulo. São Paulo-SP.

MARTON, F., HOUNSELL, D. \& ENTWISTLE, N. J. (Orgs.) (1984). The experience of learning. Edimburgo: Scotish Academic Press.

NIST, S. L. \& SIMPSON, M. L. (1987). Facilitating transfer in college reading programs. Journal of Reading, 30 (7), 620-625.

OLIVEIRA, K.L. (2001). Compreensão, leiturae desempenho acadêmico com conteúdos específicos no curso de psicologia. Trabalho de Conclusão de Curso - Curso Psicologia do Centro de Ciências Humanas e Sociais da Universidade São Francisco, Itatiba-SP.

OLIVEIRA, K. L. \& SANTOS, A. A. A. (2003). Compreensão em leitura e avaliação da aprendizagem em universitários. Manuscrito submetido à publicação na revista Psicologia: Reflexão e Crítica.

OLIVEIRA, M. H. M. A. (1996). Funções da leitura para estudantes de graduação. Psicologia Escolar e Educacional, 1 (6), 61-68.

PELLEGRINI, M. C. K. (1996). Avaliação dos níveis de compreensão e atitudes frenteà leitura em universitários. Dissertação de Mestrado. Programa de Estudos Pós-graduados em Educação. Universidade São Francisco, Bragança Paulista-SP. 
PINHEIRO, A. M. V. (1994). Leitura e escrita: uma abordagem cognitiva. Campinas: Psy.

SAMPAIO, I. S. \& SANTOS, A.A.A. (2002). Leitura e redação entre universitários: Avaliação de um programa de intervenção. Psicologia em Estudo, 7 (1), 31-38.

SAMPAIO, T. S. (1982). Teste de procedimentos para treino em leitura crítica e criativa: Um estudo experimental com universitários. Dissertação de Mestrado - Universidade Federal da Paraíba. João Pessoa-PB.

SANTOS, A. A. A. (1990). Compreensão em leitura na universidade: um estudo comparativo entre dois procedimentos de treino. Estudos de Psicologia, 2 (7), 39-53.

SANTOS, A. A. A. (1991). Desempenho em leitura: um estudo diagnóstico da compreensão e hábitos de leitura em universitários. Estudos de Psicologia-PUC-Campinas, 8 (1), 6-19.

SANTOS, A. A. A. (1997). Psicopedagogia no $3^{\circ}$ grau: Avaliação de um programa de remediação em leitura e estudo. Pro-Posições, 8 (1), 27-37.

SANTOS, A. A. A., PRIMI, R., VENDRAMINI, C. M. M., Taxa, F., LUKJANENKO, M. F., SAMPAIO, I. S., ANDRAUS Jr. S., KUSE, F. K. \& BUENO, C. H. (2000). Habilidades básicas de ingressantes universitários. Revista Avaliação, 16 (2), 33-45.

SANTOS, A. A. A., PRIMI, R., TAXA, F. \& VENDRAMINI, C. M. (2002). O Teste de Cloze na avaliação da compreensão em leitura, Psicologia: Reflexão e Crítica, 15 (3), 549-560.

SHIGUNOV, V. (2000). Reflexões sobre os testes físicos em alunos universitários. Revista Eletrônica do Estudo do Movimento Humano - Kinein, 1 (1). [citado 24 de março de 2003]. Disponível na World Wide Web: http:// kinein.ufsc.br

SISTO, F. F. (2001). Rendimento acadêmico e processos cognitivos: algumas mudanças no paradigma da avaliação. Em F. F. Sisto, E. T. B. Sbardellini \& R. Primi (Orgs.), Contextose questões da avaliação psicológica. (pp. 117-134). São Paulo: Casa do Psicólogo.

SMITH, F. (1989). Compreendendo a leitura: Uma análise psicolingüística da leitura e do aprender a ler. Tradução de Daise Batista. Porto Alegre: Artes Médicas.

SORDI, M. R. L. (2000). Problematizando o papel da avaliação da aprendizagem nas metodologias inovadoras naárea da saúde. Revista de Educação PUC-Campinas, 9, 52-61.

SOUSA, C. P., DEPRESBITERIS, L., FRANCO, M. L. P. B. \& SOUZA, S. Z. L. (1995). Avaliação do rendimento escolar (5 $5^{\mathrm{a}} \mathrm{ed}$.). Campinas: Papirus.

SPIRES, H. A. \& DONLEY, J. (1998). Prior knowledge activation: Inducing Engagement with informational texts. Journal of Educational Psychology, 90 (2), 249-260.

SPIRES, H. A., WILLIAMS, J. B., JACKSON, A. \& HUFFMAN, L. E. (1999). Levelling the academic playing field through autobiographical reading and writing. Journal of Adolescent and Adult Literacy, 42 (4), 296-304.

SUEHIRO, A. C. B. \& SANTOS, A. A. A. (2002). Compreensão de leitura entre universitários: Comparação entre ingressantes e concluintes de psicologia [Resumo]. Em Pesquisa Científica no Brasil: Esfera Pública e Privada, Resumos VIII Encontro de Iniciação Científica (p.44). Bragança Paulista: Pró-Reitoria de Pesquisa e Pós-Graduação Stricto Sensu da Universidade São Francisco.

TAYLOR, W. L. (1953). Cloze procedure: a new tool for measuring readability. Journalism Quarterly, 30, 415-433.

VERÍSSIMO, L. F. (1995). Desentendimento. Ícaro Revista de bordo da Varig, n. 136. Ano XII.

WITTER, G. P. (1997). Psicologia, leitura e universidade. Campinas: Alínea.

Recebido para publicação 3 de outubro de 2003 e aceito em 9 de março de 2004. 


\section{TESTE DE CLOZE 1}

Instruções: O texto abaixo apresenta algumas lacunas. Por favor, leia o texto todo e depois volte ao início e preencha as lacunas com as palavras que julgar mais adequadas, levando em consideração o assunto apresentado. Obrigado pela colaboração!

\section{DESENTENDIMENTO}

Texto adaptado - Luís Fernando

Veríssimo Ícaro - Revista de bordo da

Varig. n. 136. 1995. Ano XII.

A comunicação com garçons pode ser uma provação em qualquer parte do mundo. Costumo tomar leite frio, de manhã. Em Tóquio, na primeira ........ em que nos aventuramos ..... tomar café fora do fui munido da palavra para leite. Miruku, ou parecida. Experimentei-a no que me devolveu um cheio de perplexidade. Tentei novo, em várias flexões. acertei: era preciso dizer ..... palavra rapidamente. Veio o Quente. Não sei que usei para dizer que ...... queria frio - duvido que me abraçado e simulado tremedeira, o que só 0 garçom sair atrás ....... alguma corrente de ar dentro do restaurante, mas entendeu, levou o copo ..... o trouxe de volta. pedras de gelo dentro leite. Um japonês que nosso desentendimento de uma ao lado se ofereceu ajudar. Traduziu meu pedido 0 garçom. Tudo esclarecido. a intermediação enquanto o voltava para a cozinha 0 copo e pouco ................ o trazia de volta. a ameaça à paz e à amizade entre

povos, levantei o copo direção do tradutor num agradecido. O leite estava Não adianta reclamar se a um restaurante de e pedimos um prato sofisticado. Há que se com o hambúrguer e uma sacolinha de batata

Em Budapeste entramos num em que o menu em húngaro e alemão, ..... o húngaro é tão que entendemos em alemão. Não tive dificuldade em me fazer entender pelo garçom. Apontei com o dedo para a única palavra em alemão que qualquer pessoa precisa saber, além de bite e danke: forelle. Quer dizer truta. Eu poderia andar pela Alemanha comendo trutas em todas as refeições - salvo no café da manhã, claro. São as melhores do mundo, e não havia razão para as trutas húngaras não serem parecidas. Não fiquei sabendo. Não havia forelle em qualquer língua no restaurante. Acabei apontando com o dedo para a palavra com menos consoantes que vi, e que acabou sendo o nome de uma almôndega do tamanho aproximado de uma granada. Sobrevivi.

$$
\text { Você já conhecia esse texto? ( ) Sim （ ) Não }
$$




\section{TESTE DE CLOZE 2}

Instruções: O texto abaixo apresenta algumas lacunas. Por favor, leia o texto todo e depois volte ao início e preencha as lacunas com as palavras que julgar mais adequadas, levando em consideração o assunto apresentado. Obrigado pela colaboração!

\section{A NOVA CLASSE DOMINANTE}

Texto adaptado - Carlos Heitor Cony Revista República no 17/1998 - Ano II Texto adaptado

Até meados deste século, não havia tempo para ser jovem. Saía-se da infância (em que tudo era mais ou menos proibido ou permitido) e entrava-se na fase adulta, numa maturidade responsável e antecipada, decorrente da universidade, do primeiro emprego, do serviço militar ou do casamento precoce. A faixa que mediava duas idades era pejorativamente de "cachorro maluco", cujo era o adolescente com rosto coberto de espinhas .. as mãos calejadas de . .... Não tinha hora nem Se comprava uma roupa, teria de ser necessariamente pois, a cada mês, ...... jovem espichava. O mesmo para os sapatos e idéias. "Mais tarde", eles direito a roupas, sapatos ..... idéias definitivas.

Acontece que, ......... muita consciência do que fazendo, no início, eles lutavam pelo direito de levados a sério. Pouco pouco, tornaram-se uma com uma consciência específica, ética e uma estética . Enquanto os adultos cada mais se isolam em condomínios fechados, em suas abastecidas de TV a , os jovens são gregários, -se uns aos outros com desespero para, juntos - e como são os consumidores da vida moderna, ditam o que a , o comércio, a moda ..... o lazer devem produzir e Não adianta reclamar se a um restaurante de e pedimos um prato sofisticado. Há que se com o hambúrguer e uma sacolinha de batata

Na loja de disco, pedir um CD clássico causa estupor ao gerente, que nunca ouviu falar em Schumann ou Mahler. Por que não levar um U2 que fez tanto sucesso e provocou tanto engarrafamento?

Na base da pirâmide, pela expressão numérica, o jovem empurrou o vértice não exatamente para cima, como seria lógico. Empurrou-o para fora. O adulto desconfia de que está sobrando. E mais tempo fica em casa, agarrado a valores que cada vez valem menos.

$$
\text { Você já conhecia esse texto? ( ) Sim （ ) Não }
$$




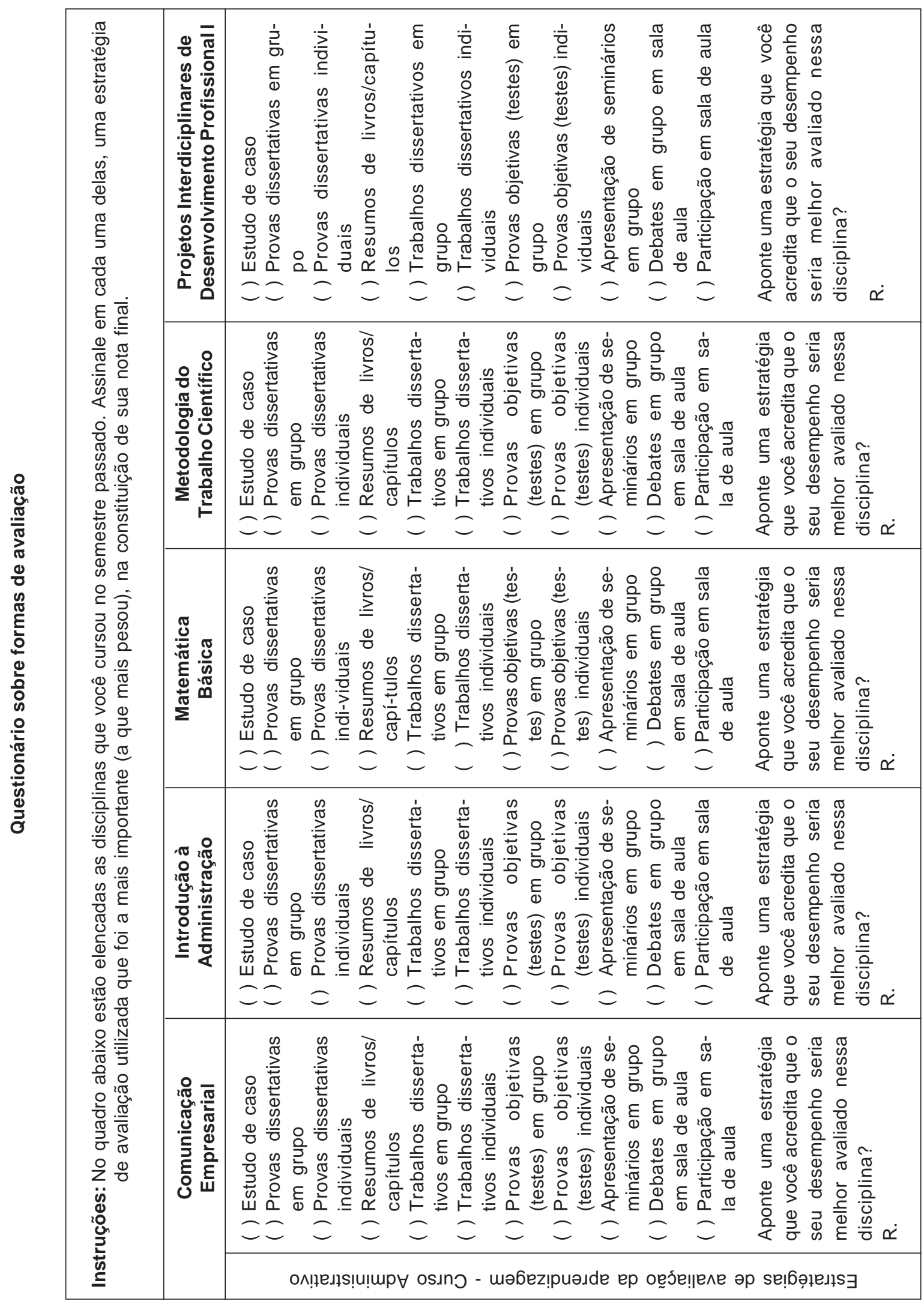


